\title{
Stigmatization by nurses as perceived by substance abuse patients: A phenomenological study
}

\author{
J ustin A. Sleeper' ${ }^{1}$, Shelley S. Bochain ${ }^{2}$ \\ 1. Department of Inpatient Psychiatry, The William W. Backus Hospital, USA. 2. Department of Nursing, Eastern \\ Connecticut State University, USA
}

Correspondence: J ustin A. Sleeper. Address: 326 Washington Street, Norwich, CT 06360, USA. Email: jsleeper@wwbh.org.

Received: July 19, 2012

Accepted: August 30, 2012

URL: http://dx.doi.org/10.5430/jnep.v3n7p92

DOI : $10.5430 /$ jnep.v3n7p92

Online Published: January 15, 2013

\section{Abstract}

Background: Caring is a central concept to nursing. Nurses are well known for their caring attitudes and professional skills. However, nurses can also follow the views of society and stigmatize vulnerable populations of patients such as SA patients. The result could be poor quality of nursing care with consequent harm to the patient. The purpose of this study was to broaden the understanding of nurses who care for substance abuse (SA) patients by revealing real-life experiences of stigma as perceived by SA patients. The narratives of patients who perceive themselves stigmatized may lead to improved client-nurse interactions, empathy, and care.

Methods: The research design for this study was qualitative phenomenological method. The study sample included five adults currently enrolled in a residential substance abuse treatment program for treatment of substance abuse/dependence or having been enrolled in such a program within six months prior who engaged in a personal open-ended interview with the researcher. All interviews were recorded for accuracy as well as additional handwritten researcher notes. All interviews were transcribed from the recordings to paper verbatim. Central themes and relationships were exhaustively searched for until they emerged.

Results: A common theme that emerged from the data was experiences of stigmatizing behaviors from nurses, counsellors, therapists, doctors, and other ancillary staff within residential substance abuse programs including the feeling that treatment staff was placing their own needs above those of the clients. Another common theme was the experience of feeling that the treatment setting limited or eliminated their personal freedom. Caring behaviors of treatment providers were also described by participants.

Conclusions: The lived experience of patients includes feelings of being stigmatized by the behaviors and actions of some of their healthcare providers, including some nurses. Stigmatizing behaviors and actions decrease patient comfort and increase patient anger and frustration. Patients also feel that the residential treatment setting needlessly inhibits personal freedom; they compare it to jail or the military. These feelings increase the risk of the patient leaving treatment impulsively, acting inappropriately, or refusing to return to particular treatment settings. Conversely, patients can feel cared for by some of their healthcare providers in residential substance abuse treatment as well. Caring behaviors increase patient comfort, help alleviate frustration, and promote positive patient outcomes.

\section{Key words}

Stigma, Nurses, Substance abuse, Patients 


\section{I ntroduction}

Addiction is a highly prevalent problem in the United States. Its effects are costly to society and devastating to individuals and families. An estimated 19.5 million Americans use illicit drugs and 15.9 million reported being heavy drinkers of alcohol ${ }^{[1]}$. Addiction is associated with increased health problems, increased crime rates, and decreased productivity. Substance abuse disorders are found to also increase morbidity and mortality rates leading to an estimated 100,000 deaths per year ${ }^{[2]}$. The annual cost to society as a result of addiction is estimated at $\$ 184$ billion ${ }^{[1,3,4]}$.

Many people in today's society feel that substance abuse (SA) is not an illness. If SA is not an illness but a personal choice, then how would formal treatment help? Many people feel that formal SA treatment is not helpful, and that treating SA is a matter of a person's will power alone. Others report that abusing illegal and addictive substances is a personal choice, and one that most people decide not to make ${ }^{[1]}$. When SA is viewed in this context as a personal choice that people make, then those people who choose SA suffer the social consequences of that choice. Society judges people with addiction as dangerous and unpredictable. Many nurses do not have the knowledge to identify and manage patients with addiction issues and substance withdrawal. This emotional response from an uninformed society, including nurses, often leads to higher levels of stigma against people with addiction problems ${ }^{[5]}$.

This fear of stigma imposed by community members prevents many people from seeking proper treatment for their addictions which in turn compounds their health risks. When people do seek addiction treatment, they may find themselves stigmatized by the healthcare providers who are supposed to be treating them. Caring is a central concept to nursing. Nurses are well known for their caring attitudes and professional skills. However, nurses can also follow the views of society and stigmatize vulnerable populations of patients such as SA patients. The result could be poor quality of nursing care with consequent harm to the patient.

The purpose of this study was to broaden the understanding of nurses who care for SA patients by revealing real-life experiences of stigma as perceived by SA patients. The narratives of patients who perceive themselves stigmatized may lead to improved client-nurse interactions, empathy, and care. The research questions of this study were:

1) What is the lived experience of perceived stigma by nurses for patients in residential SA treatment?

2) What is the impact of perceived stigmatization by nurses on SA patients in residential SA treatment?

3) How does perceived stigmatization by nurses affect the overall health and well being of SA patients?

\section{Literature review}

A study by Crisp et al. ${ }^{[5]}$ reviewed public opinion of people with mental illness in England. This study included both addiction disorders and mental illness. They found that the public strongly viewed those with schizophrenia, alcoholism, and drug addiction as dangerous, unpredictable, and a threat to society. A significant number of the respondents felt that those with addiction were to blame for their own disorders and could help themselves through stronger will.

Fortney et al. ${ }^{[6]}$ suggest that stigma is a barrier to treatment for alcohol abusers. Stigma is dichotomized into public stigma and self-stigma. Public stigma refers to the negative attitudes, labeling, and devaluation of groups based on preconceived ideas from society as a whole. Self-stigma refers to the act of individuals from a stigmatized group internalizing the devaluation and labels from the public stigma. As a result, people who abuse alcohol may not seek treatment due to perceived public stigma and the self-stigma of being an alcoholic ${ }^{[6]}$.

Another study by Young, Stuber, Ahern, and Galea ${ }^{[7]}$ showed that $75.3 \%$ of their sample of illicit drug users had been discriminated against because of their SA. The study also showed that the result of this discrimination was manifested by poor mental health and depression, chronic stress, and other related chronic health problems. 
Research is limited concerning nurses who stigmatize their SA patients. Studies by Crisp et al. ${ }^{[5]}$, Fortney et al. ${ }^{[6]}$, Young et al. ${ }^{[7]}$, and Tsai ${ }^{[8]}$ found evidence of stigmatization of people with SA problems. The study by Pillon and Laranjeira ${ }^{[9]}$ studied nurses' attitudes toward alcoholism in Brazil. The study also examined the effect of nursing education on nurses' attitudes. The study found that nurses, nursing students, and nursing teachers held neutral or negative attitudes toward patients who had alcohol problems. The most significant factor found for these attitudes was the lack of adequate education specific to SA on all levels. While the focus of this study was on nursing education, there was the presentation of nurses stigmatizing alcohol patients ${ }^{[9]}$. Tsai ${ }^{[8]}$ reports lack of a good nurse-patient relationship and lack of sufficient knowledge prevents nurses from taking alcohol assessments seriously in the Emergency department setting.

\section{Patients and methods}

\subsection{Population selection}

The study sample included five adults currently enrolled in a residential substance abuse treatment program for treatment of substance abuse/dependence or having been enrolled in such a program within six months prior. Each participant was diagnosed with either Substance Abuse or Substance Dependence according to DSM-IV criteria ${ }^{[10]}$. People who were diagnosed with psychotic disorders or cognitive disturbances were not included. Sampling was purposeful and included both men and women. Subjects were currently enrolled in residential SA treatment or enrolled in such a program within six months prior to study participation. Age of participants ranged from 18 to 50 years old. All participants spoke English and had cognitive ability to recall and describe their personal experiences in SA treatment. Participation was voluntary and participants were not paid for entering this study.

The rights and confidentiality of the research participants were taken into account at every stage of this research study. Each participant signed informed consent to participate in this voluntary research study. Participants were informed of the study purpose, their rights involved with this study, the fact that they will not be paid for participation, and their right to opt out of participation at any point of the study prior to signing study consent. Potential participants were informed of how any information they provide during this study will be utilized. Permission was obtained to use direct quotes for any publications. The researcher ensured that potential participants fully understood the risks and benefits of taking part in this research study. Every effort was made to accommodate the needs of a study participant and protect their confidentiality and individual rights before, during, and after the research process. Prior and during interviewing, participants were given an ample opportunity to ask questions of the researcher. At varying points during the interview process, the researcher evaluated participants' desire to continue in the study and give them ample opportunity to opt out of participation without penalty. Upon study completion, participants were given the opportunity to discuss their experiences, ask questions, and receive support from the researcher.

\subsection{Data collection}

Each participant in this research study engaged in a personal open-ended interview with the researcher. The participants were encouraged to describe their lived experiences in residential substance abuse treatment, stigma associated with diagnosis of substance abuse/dependence, and any perceived stigma from nurses caring for them. Clarifying statements were used in order to assist participants when they describe life experiences without guiding their discussion. Questions also served the purpose of eliciting more detailed information from the participant ${ }^{[11]}$. Open-ended questions were asked until answers and data begins to repeat consistently or until the participants felt they had finished. All interviews were recorded for accuracy as well as additional handwritten researcher notes. All interviews were transcribed from the recordings to paper verbatim. Interviews were listened to immediately after in order to check for accuracy and clarity of information. 


\subsection{Data analysis}

Once participant interviews were complete, the data was written verbatim. The researcher became immersed in the data from participants' interviews in order to find common themes, statements, and ideas upon reflection of the data. This was accomplished by reading and re-reading the written records of the data. Common themes, statements, and ideas were written onto note cards. These common themes, statements, and ideas were then analyzed for common relationships. Central themes and relationships were exhaustively searched for until they emerged. A comprehensive written final description was the product of this process ${ }^{[11]}$. Descriptive statistics were not used in this study.

\section{Results}

Common themes of stigmatization and caring emerged from the interviews. These themes associated with stigma, lack of freedom, and caring.

\section{Theme 1: Stigmatizing behaviors}

Participants recalled stigmatizing behaviors during their stay in residential substance abuse treatment. Participants reported experiences in which treatment staff disregarded their physical and emotional needs. Other behaviors included delaying and ignoring requests, yelling at clients, wrongful accusations, and giving clients no personal attention. Some of the participants also reported consequences of this perceived disregard. Direct participant quotes:

"They were quite shaming."

"No regard for your personal anything."

"It just seemed, this is another theme of these drug places: there's no respect given to you as an adult. Or even a child should be treated with more respect. There's no acknowledgment that you came there because you want recovery. No one...I wasn't ordered there by anybody."

“There was nothing like, "How are you feeling?” No attention to feelings...at all...in any of these places.”

"There are some places where you go where you feel like you're just another number or just another paycheck coming from the state."

"I was at a detox and I was feeling rotten. There was one detox I went to like that, I try and talk to the nurse, and the nurse won't do anything about it."

"...they know they got to do it, but they got other stuff to do, so they prioritize instead of the clients getting their food in order, they get their paperwork in order."

"And I was going...that was a bad detox. They wouldn't even give me medication. I'd beg for medication, and they wouldn't give me any. They told me to just suffer it out. So, after three days, I signed myself out."

\section{Theme 2: Lack of freedom}

Participants reported experiences in residential substance abuse treatment that felt like they had lost their freedom. They reported feelings of being trapped, in jail, or in the military. Participants also reported experiences of overwhelming lack of personal time and time for self. Direct participant quotes: 
"Another thing; I felt personally, was that I was trapped. You know, I felt trapped in these places because...even though I was there voluntarily. I stayed because, well I thought I should stay, you know, maybe it will work, first of all."

"There were no options. You know? It was just, felt like we were in the military...would feel”

"I feel angry. I feel, I feel...stuck and angry. I even told her, 'Gosh, I'm kind of regretting that I came here. I walked in here, and of my own volition, you know, to get help because...now you're sort of telling me it's my way or...it's my way.' Because I told her what I wanted to do, but I guess it wasn't good enough. You know, I'm definitely not planning to have her as my doctor as soon as possible."

"But it's places like that where it's group, group, group, group. It's groups and you're stuck in the house all day. That's your whole life. And there's not a whole hell of a lot to do."

"I really do, I feel like a prisoner sometimes. I look at the door, and I think if I run, they're gonna catch me. Like, I don't need to run, but it's just that thought of being trapped, and I've always had a problem with that feeling."

“So, being locked down, it’s kind of scary. You know? Because you don't have a choice. It's not your choice anymore."

\section{Theme 3: Caring}

Participants did recall instances when they felt cared for by treatment staff. They reported staff attributes, behaviors, and experiences that had a positive influence on them.

"What made him wonderful was, he was sensitive to me. He listened. He listened to everything I said. And he responded. You know, he was, he responded like I was a meaningful person.”

"Or some of them will make phone calls for you, they'll advocate for you, and stuff like that. Like, they care what you're gonna do afterward.”

"It's like people went out of their way to learn your name and call you by name, and stuff like that. Say 'hi' and 'bye' to you."

“A place like___ if I go to the nurse and tell them I'm feeling bad, she'd immediately stop what she's doing, check the computer for the last time she gave me

"What, and what she could give for me now. Immediately alleviate the situation to try and make me more comfortable."

“...or they think you're a person once they get to know you and see how you act; see you as a feeling person and do what they can to help."

"You know, he would just talk to us just like he was one of us."

\section{Discussion}

Caring is a central concept to nursing. Nurses are well known for their caring attitudes and professional skills. However, nurses can also follow the views of society and stigmatize vulnerable populations of patients such as SA patients. The result could be poor quality of nursing care with consequent harm to the patient. The purpose of this study was to broaden 
the understanding of nurses who care for substance abuse patients by revealing real-life experiences of stigma as perceived by SA patients. The narratives of patients who perceive themselves stigmatized may lead to improved client-nurse interactions, empathy, and care.

Three common themes became apparent as the researcher became immersed in the data and the written interviews were analyzed. The first theme that emerged was "stigmatizing behaviors.” The stigmatizing behaviors that the participants recalled were not limited to nurses. Participants felt they were also stigmatized by doctors, mental health workers, counselors, social workers, and ancillary staff as well as nurses. Four out of the five participants reported experiences in which treatment staff disregarded their physical and emotional needs. In some instances, patients felt that the only reason for provider-patient interaction was to satisfy the needs of the providers. Other behaviors included delaying and ignoring requests, yelling at clients, wrongful accusations, and giving clients no personal attention or empathy. Some of the participants also mentioned feeling like they were given no respect. These stigmatizing behaviors caused patients to feel isolated, alone, frustrated, angry, and destructive. Only one subject did not recall experiencing stigmatizing behaviors while enrolled in residential substance abuse treatment. However, this is the first enrollment in residential substance abuse treatment for this subject which limits her experiences.

The second common theme that emerged from the data analysis was "lack of freedom." All of the participants described residential substance abuse treatment like jail or the military that needlessly inhibits their personal freedom. Patients in treatment felt stuck, trapped, and limited in their options. They felt trapped even though often times they were in treatment voluntarily and could sign out at any time. Four of the five participants mentioned the need for personal time away from other patients. This free time was limited by excessive groups, chores, and other responsibilities along with highly regimented schedules. The lack of freedom, autonomy, and options caused patients to set aside motivation for treatment and increased desires to leave. In some instances, patients felt that treatment was forced on them due to the treatment structure. Three participants felt forced into treatment. They complained about feeling forced to do something they were not entirely ready to do. These patients agreed that forcing them to do something they did not want to do would be counterproductive. Lack of meaningful interactions with treatment staff also contributed to feelings of treatment being like jail.

These two common themes describe how SA patients feel stigmatized in residential substance abuse treatment. Patients enroll voluntarily or involuntarily into SA treatment for help with their variety of addiction issues. Rather than receiving help, patients can find themselves treated poorly by staff, neglected, and disrespected. The treatment settings themselves are sometimes not conducive to recovery by limiting freedom, autonomy, and personal options. Consequently, some patients who desperately need help experience poor treatment in an un-friendly environment. The stigmatizing feelings expressed by the participants were consistent with available literature ${ }^{[5-9]}$.

The third common theme that emerged from the data was "caring." All of the participants recalled experiences when they felt cared for by treatment staff. Patients felt cared for when staff listened, gave attention, accommodated needs, remained respectful, and empathized with them. Patients felt care from small gestures such as saying "hi” and "bye." They also felt cared for by staff when they felt they were not being judged inappropriately or stereotypically. In some instances, patients felt care when staff took an interest and joined in their activities. Two participants felt most cared for by counsellors who were recovered addicts due to the complete understanding of the nature of addiction having also experienced it. These patients felt comfort knowing they truly had something in common with their counsellors. Having counselors who were recovering addicts also reduced the possibility of judgment and preconceived ideas which helped ease anxiety. To be treated as an individual was an important aspect to care for all the participants.

Nurses are well known for their caring attitudes and professional skills. However, nurses can also follow the views of society and stigmatize vulnerable populations of patients such as SA patients ${ }^{[5-8]}$. This can result in poor quality nursing care and cause serious consequent harm to the patient. Persons seeking help for addiction issues are entitled to the same 
care afforded to other persons seeking help for medical and other ailments. It is important for nurses to understand how patients truly feel about the treatment they receive. Literature supports the idea that lack of education and training contribute to negative attitudes toward SA patients ${ }^{[8,9]}$. It is also important for nurses to understand how holistically their care, or lack of care, can influence their patients' lives. Nursing care tends to be holistic in nature, but when certain aspects of the human are ignored such as the psychosocial aspect, quality nursing care does not occur. This study shows how important participants of this study feel that nurse-patient relationships and interactions are to them. While the focus of this study was patients in residential SA treatment, persons with SA issues are found in all healthcare settings. It is important for all nurses and healthcare providers to understand the experiences of SA patients so this population can receive quality healthcare no matter the setting and treat all patients with respect and empathy regardless of diagnosis, history, or background.

\section{References}

[1] Bailey, K. P. The brain’s rewarding system \& addiction. Journal of psychosocial nursing and mental health services. 2004; 42(6): 14-18.

[2] Britt, A. B. African americans, substance abuse and spirituality. 2004. Available from: http://www.minoritynurse.com/features/health/07-21-04d.html.

[3] Roxburgh, A. \& Degenhardt, L. Characteristics of drug-related hospital separations in Australia. Drug and Alcohol Dependence. 2008; 92: 149-155. PMid:17884302 http://dx.doi.org/10.1016/j.drugalcdep.2007.07.020

[4] Laudet, A. \& White, W. What are your priorities right now? Identifying service needs across recovery Stages to inform service development. Journal of Substance Abuse Treatment. 2010; 38: 51-59. PMid:19631490 http://dx.doi.org/10.1016/j.jsat.2009.06.003

[5] Crisp, A.H., Gelder, M.G., Meltzer, H.I., \& Rowlands, O.J. Stigmatisation of people with mental illnesses. The British Journal of Psychiatry. 2000; 177: 4-7. PMid:10945080 http://dx.doi.org/10.1192/bjp.177.1.4

[6] Fortney, J., Mukherjee, S., Curran, G., Fortney, S., Han, X., \& Booth, B.M. Factors associated with perceived stigma for alcohol use and treatment among at-risk drinkers. The Journal of Behavioral Health Services \& Research. 2004; 31: 418-429. PMid:15602142

[7] Young, M., Stuber, J., Ahern, J., \& Galea, S. Interpersonal discrimination and the health of illicit drug users. American Journal of Drug and Alcohol Abuse. 2005; 31(3): 371-391. PMid:16161724 http://dx.doi.org/10.1081/ADA-200056772

[8] Tsai, Y. Nurses' perceived facilitators and barriers to assessing for alcohol use in Taiwan. Journal of Clinical Nursing. 2009; 18: 2078-2086. PMid:19220620 http://dx.doi.org/10.1111/j.1365-2702.2008.02590.x

[9] Pillon, S.C. \& Laranjeira, R.R. Formal education and nurses' attitudes towards alcohol and alcoholism in a Brazilian sample. Sao Paulo Med Journal. 2005; 123(4): 175-180. http://dx.doi.org/10.1590/S1516-31802005000400004

[10] American Psychiatric Association. Diagnostic and statistical manual of mental disorders (6th ed.). 1999; Washington, DC: American Psychiatric Association.

[11] Speziale, H.J. \& Carpenter, D.R. Qualitative research in nursing: Advancing the humanistic imperative. Philadelphia: Lippincott Williams \& Wilkins. 2003. 